University of South Carolina

Scholar Commons

2005

\title{
A New Circularly Polarized Rectenna for Wireless Power Transmission and Data Communication
}

\author{
Mohammod Ali \\ University of South Carolina - Columbia, alimo@engr.sc.edu
}

G. Yang

Roger A. Dougal

University of South Carolina - Columbia, dougal@engr.sc.edu

Follow this and additional works at: https://scholarcommons.sc.edu/elct_facpub

Part of the Electrical and Computer Engineering Commons

Publication Info

Published in IEEE Antennas and Wireless Propagation Letters, Volume 4, 2005, pages 205-208.

http://ieeexplore.ieee.org/xpl/Recentlssue.jsp?reload=true\&punumber=7727

(C) 2005 by IEEE

This Article is brought to you by the Electrical Engineering, Department of at Scholar Commons. It has been accepted for inclusion in Faculty Publications by an authorized administrator of Scholar Commons. For more information, please contact digres@mailbox.sc.edu. 


\title{
A New Circularly Polarized Rectenna for Wireless Power Transmission and Data Communication
}

\author{
Mohammod Ali, Senior Member, IEEE, G. Yang, and R. Dougal, Senior Member, IEEE
}

\begin{abstract}
Small distributed wireless sensors are becoming very important in many aspects of our lives. While low data rate passive sensors operate with little energy there is a need for moderate to high data rate distributed sensors for infrastructure monitoring and other applications. Such sensors will require their batteries or onboard capacitors to be charged when depleted for proper operation. In this letter, we propose a circularly polarized (CP) microstrip patch antenna that can function as a WLAN antenna in the 5.15-5.35 GHz and as a rectenna at $5.5 \mathrm{GHz}$.
\end{abstract}

Index Terms-Antenna, rectenna, sensor, wireless.

\section{INTRODUCTION}

$\mathbf{R}$ ECENTLY, considerable emphasis has been placed on studying the quality and safety issues of our nation's transportation infrastructures [1]-[3]. A careful evaluation of the life span and current condition of steel reinforcement tendons inside the concrete covering of a bridge is crucial to ensure public safety. The solution for this problem calls for the deployment of miniaturized embedded sensors within the bridge structure itself during the construction process. An RFID (radio frequency identification) type passive sensor utilizes a narrowband tank circuit. Thus, the presence of other metallic objects can cause a significant frequency shift as a result of which the sensor may not operate properly. Also, due to the availability of low power, only a very limited amount of data transmission is possible. In contrast, a $5-6 \mathrm{GHz}$ WLAN type sensor is not limited in data rate and does not have the constraints of a narrowband $L C$ tank circuit. However, for proper functioning of the circuitry there must be a mechanism to: 1) remotely charge the transceiver battery or capacitor as needed, and 2) send and receive data in between the embedded sensor and the interrogator.

Detecting cracks or deformations in the structure can be achieved by employing active acoustic wave transducers [1]. This information then must be sent to an appropriate destination. Traditionally, a mobile test unit (MTU) will perform the function of the interrogator. We propose that in addition to data telemetry the MTU will also deliver microwave power to the embedded wireless sensor. The power will be received and converted to dc using an on-board rectenna [4]-[6]. In

Manuscript received January 18, 2005; revised April 29, 2005. This work was supported by the U.S. Office of Naval Research under Grant N00014-02-1-0623.

The authors are with the Department of Electrical Engineering, University of South Carolina, Columbia, SC 29208 USA (e-mail: alimo@engr.sc.edu).

Digital Object Identifier 10.1109/LAWP.2005.851004

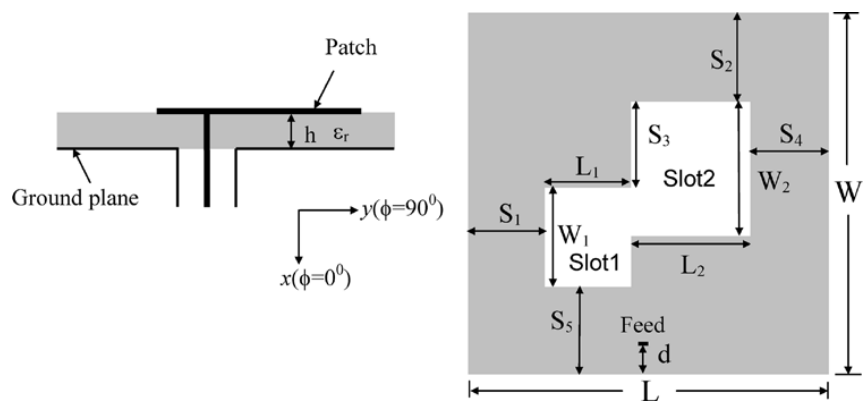

Fig. 1. Antenna geometrical configuration; cross section and top view Antenna parameters: $\mathrm{L}=14.8 \mathrm{~mm}, \mathrm{~W}=14.8 \mathrm{~mm}, \mathrm{~L}_{1}=4.1 \mathrm{~mm}$ $\mathrm{L}_{2}=5.2 \mathrm{~mm}, \mathrm{~W}_{1}=5.45 \mathrm{~mm}, \mathrm{~W}_{2}=5.8 \mathrm{~mm}, \mathrm{~S}_{1}=2.75 \mathrm{~mm}$, $\mathrm{S}_{2}=3.25 \mathrm{~mm}, \mathrm{~S}_{3}=2.85 \mathrm{~mm}, \mathrm{~S}_{4}=2.75 \mathrm{~mm}, \mathrm{~S}_{5}=3.25 \mathrm{~mm}$, $\mathrm{d}=2.83 \mathrm{~mm}, \mathrm{~h}=3.175, \varepsilon_{\mathrm{r}}=2.2$.

the future instead of MTUs one can envision stationary in-situ supervisory control sensors (installed on the surface and not embedded) in the vicinity of the embedded sensors, which will perform the functions of data communication and power delivery. Such in-situ sensors can send information to the highway administration on a continuous basis.

Recent research has shown that there are certain benefits to use circularly polarized (CP) antennas with sensors [7], [8]. Circularly polarized antennas will essentially help obtain the same dc voltage irrespective of the rotation of the rectenna. In this paper, we introduce a circularly polarized microstrip patch antenna which can function as a rectenna for wireless battery charging at $5.5 \mathrm{GHz}$ and data telemetry in the $5.15-5.35 \mathrm{GHz}$ WLAN band. Our proposed antenna is only $14.8 \mathrm{~mm}$ by $14.8 \mathrm{~mm}$ by $3 \mathrm{~mm}$ in size which can be readily integrated within a sensor circuit board.

\section{GeOMEtry of the CiRCUlarly POlARIZED PATCH ANTENNA}

The geometry of the proposed antenna along with its parameters is shown in Fig. 1. The antenna was initially designed and developed on 3.175-mm thick Duroid $5880\left(\varepsilon_{\mathrm{r}}=2.2\right)$ substrate and fed by a coaxial probe. Before fabrication the antenna characteristics were optimized for wide return loss and circular polarization bandwidth by conducting a parametric study using Ansoft HFSS. The antenna design is based on our previous work presented in [9], [10]. The two slots positioned along the left diagonal of the microstrip patch generate right-hand circular polarization (RHCP). Positioning the slots along the right diagonal generates left-hand circular polarization (LHCP). 


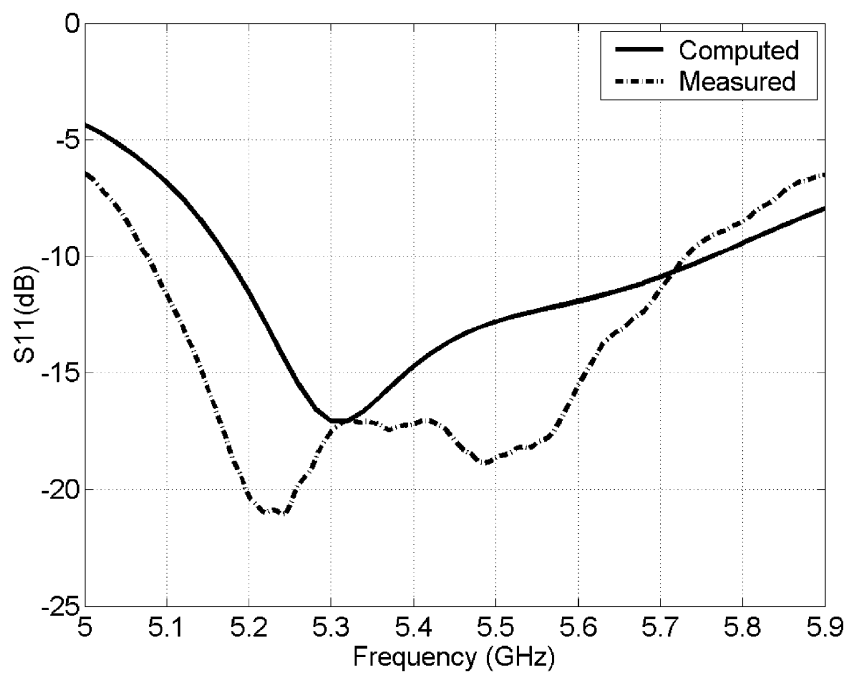

Fig. 2. Computed and measured return loss versus frequency for the proposed antenna on 3.175-mm-thick Duroid 5880 substrate.

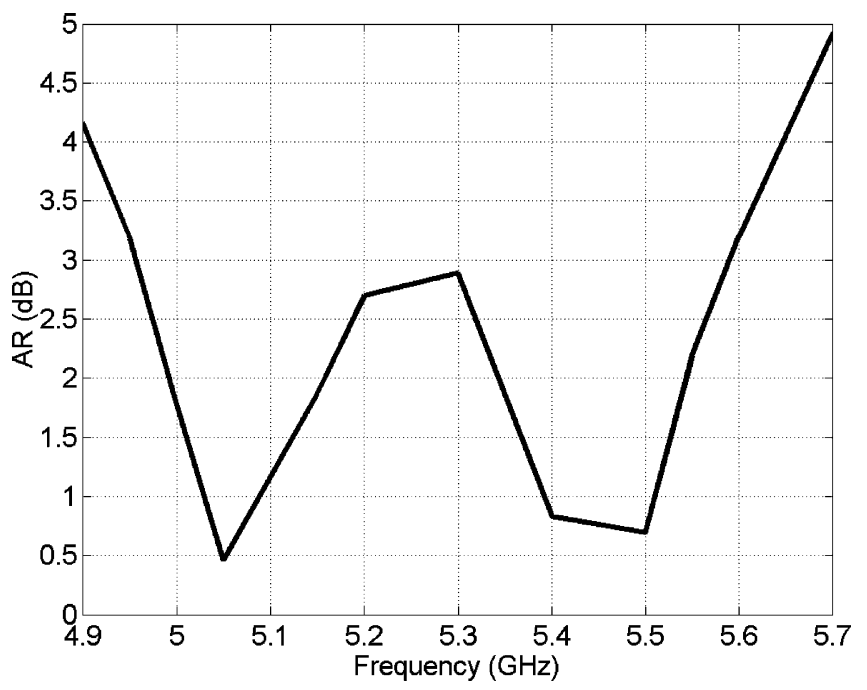

Fig. 3. Computed axial ratio of the proposed antenna on 3.175-mm-thick Duroid 5880 substrate.

\section{RESULTS}

\section{A. Antenna Characteristics}

Computed and measured $\mathrm{S}_{11}(\mathrm{~dB})$ data for the proposed antenna on 3.175-mm thick Duroid 5880 substrate are shown in Fig. 2. These data are generally in good agreement. Computed and measured bandwidths within $S_{11} \leq-10 \mathrm{~dB}$ are $11 \%$ and $12 \%$, respectively. It is clear that the measured antenna prototype supports operation in the $5.15-5.35 \mathrm{GHz}$ WLAN frequency bands.

Computed axial ratio data (at boresight) for this antenna are shown in Fig. 3. The $3 \mathrm{~dB}$ axial ratio bandwidth extends from 4.96 to $5.59 \mathrm{GHz}(12.1 \%)$, which is very good for a single-fed microstrip patch. The antenna is right-hand circularly polarized for the 5.15-5.35 GHz WLAN data communication. It is also circularly polarized for the $5.5 \mathrm{GHz}$ wireless power transmission scheme. Computed normalized radiation patterns of this antenna at $5.5 \mathrm{GHz}$ are shown in Fig. 4(a) and (b). The antenna was placed on a $40 \mathrm{~mm}$ by $40 \mathrm{~mm}$ ground plane. The $\mathrm{E}_{\theta}$ and
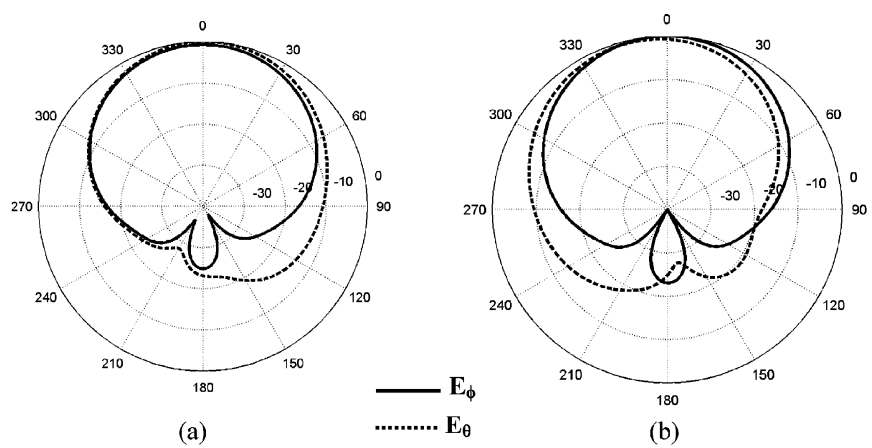

(b)

Fig. 4. Computed normalized radiation patterns of the proposed antenna on 3.175-mm-thick Duroid 5880 substrate at $5.5 \mathrm{GHz}$. (a) $\phi=0^{\circ}$. (b) $\phi=90^{\circ}$.
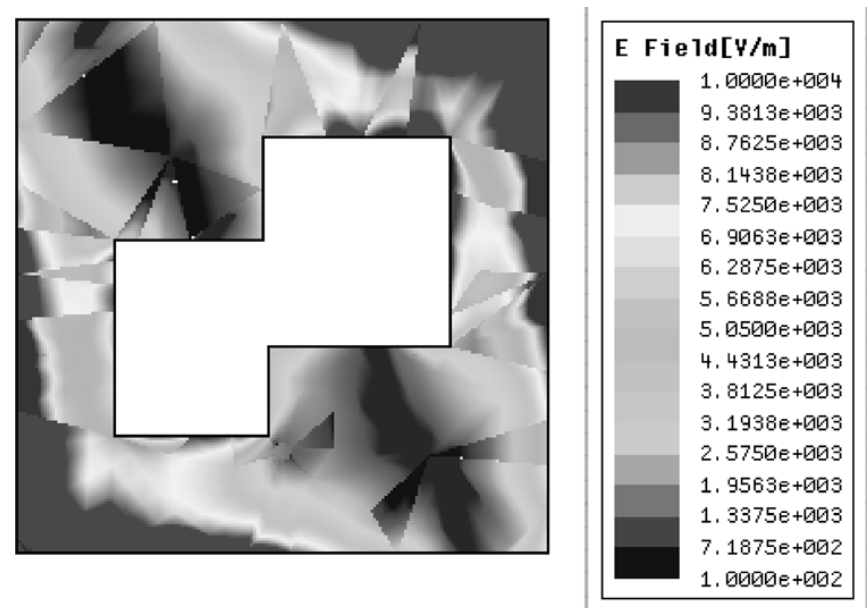

Fig. 5. Computed $\mathrm{E}$ field distribution of the proposed antenna on 3.175-mm-thick Duroid 5880 substrate at $5.5 \mathrm{GHz}$.

$\mathrm{E}_{\phi}$ components are very close to each other in magnitude as expected. The peak gain of the antenna is $8 \mathrm{dBi}$ RHCP at $5.5 \mathrm{GHz}$. The front to back ratio is $20 \mathrm{~dB}$ or better.

Computed $\mathrm{E}$ field distributions of the proposed antenna are shown in Fig. 5. Stronger fields are concentrated close to the feed with a clockwise rotation sense. The two slots create unequal lengths for two separate current paths. These current paths correspond to two hybrid operating modes which result in good return loss and axial ratio performance. This was also confirmed when E-field animation was observed in HFSS. This particular geometry with its slot orientation results in right-hand CP. If a mirror image case is considered, left-hand $\mathrm{CP}$ will result with stronger field concentration along the other diagonal.

\section{B. Rectenna Fabrication and Testing}

There has been considerable research work on rectennas for space and satellite applications [4]-[6]. Recently there has been some focus to power wireless embedded sensors using rectennas [8]. Our proposed circularly polarized microstrip patch antenna described above was used to design and develop a rectenna to demonstrate wireless power beaming at $5.5 \mathrm{GHz}$. The circuit diagram of the rectenna along with its components is shown in Fig. 6. A photograph of the fabricated prototype rectenna is also shown in Fig. 7. The test setup used to measure the rectenna performance characteristics is depicted in Fig. 8. A 5.3-5.9 GHz amplifier with $7 \mathrm{~W}$ output power was 


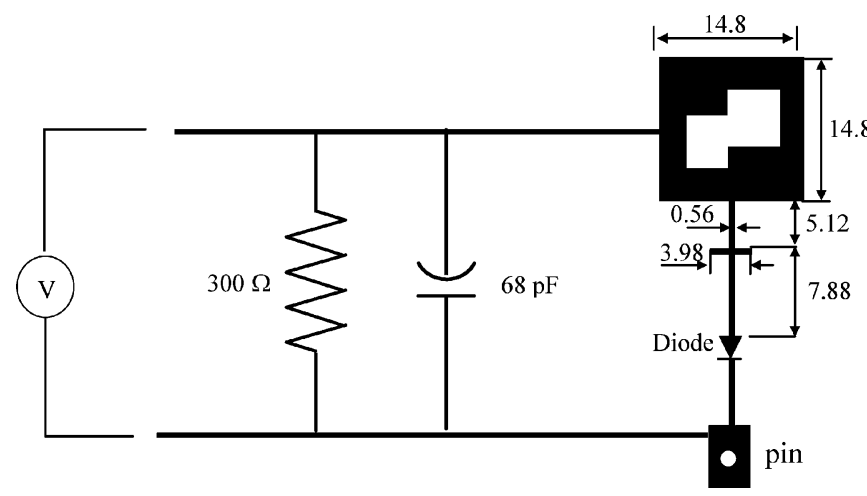

Fig. 6. Geometry and circuit diagram for the proposed rectenna consisting of an M/A com diode, $\mathrm{CP}$ antenna, and other passive components.

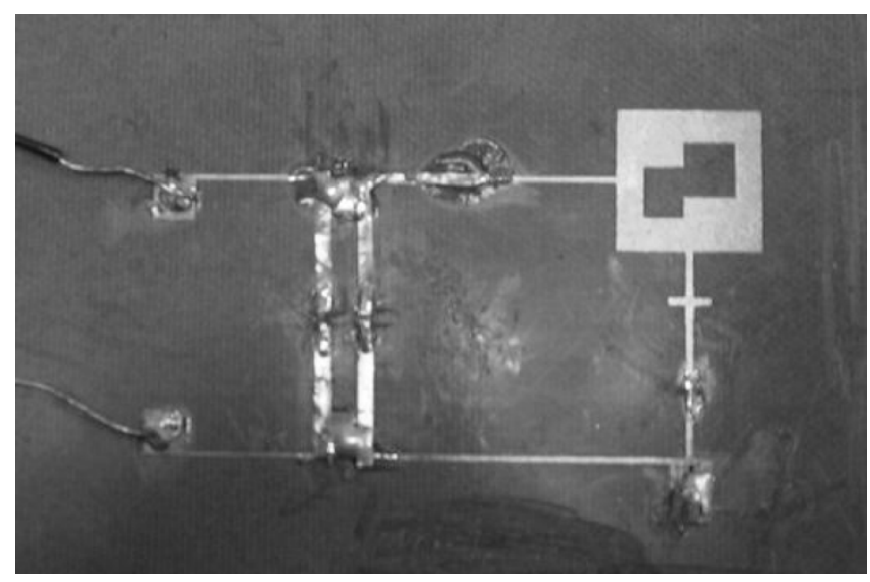

Fig. 7. Photograph of the fabricated and measured rectenna.

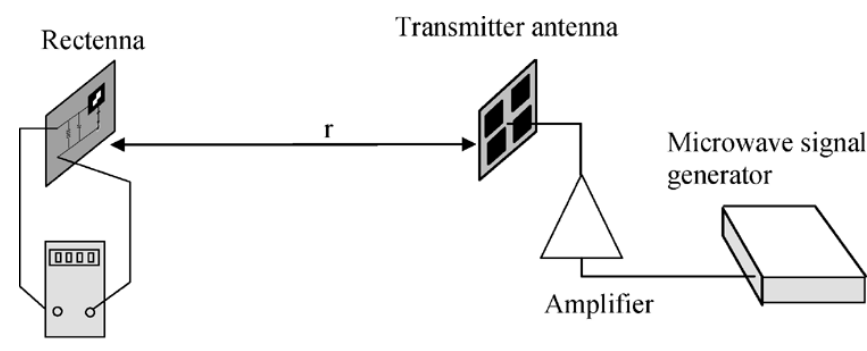

Voltmeter

Fig. 8. Rectenna measurement setup.

used with the signal generator. The amplifier was connected to a four-element linearly polarized microstrip array antenna with gain $7.6 \mathrm{dBi}$. The distance between the transmitter and the rectenna is $r$. For rectification, a high efficiency M/A COM detector diode MA4E1317 was used.

The width of the microstrip transmission line was chosen based on the input impedance of the diode $(172 \Omega)$. The line length was so chosen as to achieve a good impedance match between the diode and the antenna. The bottom side of the diode was connected to a wide stub which was shorted to the ground plane using a via. The converted dc was collected from the left edge of the patch in order to avoid direct interference with the incident waves. A $68 \mathrm{pF}$ capacitor and a $300 \Omega$ load resistor, $\mathrm{R}_{\mathrm{L}}$ were used to maximize the dc voltage output.

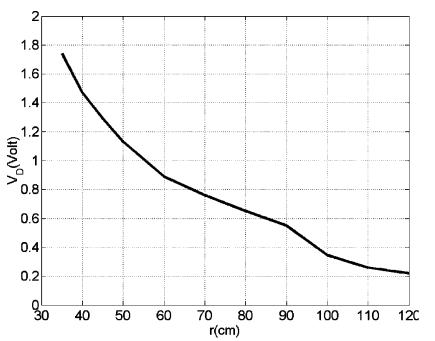

(a)

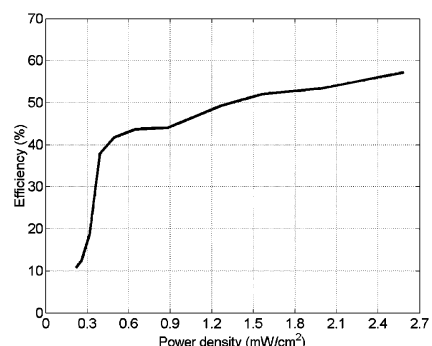

(b)
Fig. 9. Measured output voltage $\mathrm{V}_{\mathrm{D}}$ and convesion efficiency of the $\mathrm{CP}$ rectenna at $5.5 \mathrm{GHz}$. (a) Distance versus output voltage $\mathrm{V}_{\mathrm{D}}$. (b) Power density versus conversion efficiency; $\mathrm{R}_{\mathrm{L}}=300 \Omega, \mathrm{C}=68 \mathrm{pF}$.

The conversion efficiency for the CP rectenna can be calculated by [11]

$$
\eta_{R}=\frac{\frac{V_{\mathrm{D}}^{2}}{R_{\mathrm{L}}}}{P_{t} G_{t} G_{\mathrm{r}}\left(\frac{\lambda_{0}}{4 \pi r}\right)^{2} L_{\mathrm{pol}}}
$$

where $\mathrm{P}_{t}$ and $\mathrm{G}_{t}$ represent the transmit power and the gain of the transmitting array, $G_{r}$ represents the gain of the rectenna, $V_{D}$ is the voltage across the load resistor $\mathrm{R}_{\mathrm{L}}$ of the rectenna. The distance between the transmitter and the rectenna is $r$. The transmitter array and the CP rectenna has a polarization mismatch loss taken care of by the term $\mathrm{L}_{\mathrm{pol}}$. For this case, $\mathrm{L}_{\mathrm{pol}}$ can be calculated as $L_{\mathrm{pol}}=\left|\rho_{w} \cdot \rho_{a}^{*}\right|^{2}=\left|\hat{a}_{x} \cdot(1 / \sqrt{2})\left(\hat{a}_{x}+j \hat{a}_{y}\right)\right|^{2}=$ $1 / 2$ [11]. The power density, $\mathrm{P}_{\mathrm{D}}$ at the location of the rectenna is given by $P_{\mathrm{D}}=P_{t} G_{t} / 4 \pi r^{2}[8]$.

The performance of the rectenna was measured at $5.5 \mathrm{GHz}$. Measured diode voltage, $V_{\mathrm{D}}$ and conversion efficiency are shown in Fig. 9(a) and (b), respectively. Clearly with increasing distance $\mathrm{V}_{\mathrm{D}}$ decreases. For instance, $1.74 \mathrm{~V}$ dc was received for $r=35 \mathrm{~cm}$. From Fig. 9(b), it is clear that maximum conversion efficiency of $57.3 \%$ is achieved when incident power density is $2.55 \mathrm{~mW} / \mathrm{cm}^{2}$.

\section{CONCLUSION}

A circularly polarized microstrip patch antenna is introduced that can function as a WLAN antenna in the $5.15-5.35 \mathrm{GHz}$ and as a rectenna at $5.5 \mathrm{GHz}$. Two rectangular slots properly positioned along the diagonal of the square patch antenna create two hybrid operating modes which operate very close in frequency and hence help achieve wide axial ratio bandwidth. Antenna designed on Duroid 5880 substrate with single feed provides a return loss bandwidth of $12.4 \%$ and axial ratio bandwidth of $12.1 \%$, respectively. Using the proposed CP patch a rectenna was fabricated and tested at $5.5 \mathrm{GHz}$ providing a conversion efficiency of $57.3 \%$ for a load resistance of $300 \Omega$.

\section{REFERENCES}

[1] J. T. Bernhard, K. Hietpas, E. George, D. Kuchma, and H. Reiss, "An interdisciplinary effort to develop a wireless embedded sensor system to monitor and assess the corrosion in the tendons of prestressed concrete girders," in Proc. IEEE Topical Conf. Wireless Communication Technology, Honolulu, HI, Oct. 15-17, 2003, pp. 241-243.

[2] J. P. Lynch, K. H. Law, A. S. Kiremidjian, E. Carryer, C. R. Farrar, H. Sohn, D. W. Allen, B. Nadler, and J. R. Wait, "Design and performance validation of a wireless sensing unit for structural monitoring applications," Structural Eng. Mechanics, vol. 17, no. 3-4, pp. 393-408, 2004. 
[3] J. P. Lynch, A. Partridge, K. H. Law, T. W. Kenny, A. S. Kiremidjian, and E. Carryer, "Design of a piezoresistive MEMS-based accelerometer for integration with a wireless sensing unit for structural monitoring," $J$. Aerospace Eng., vol. 16, no. 3, pp. 108-114, 2003.

[4] W. C. Brown and E. E. Eves, "Beamed microwave power transmission and its application to space," IEEE Trans. Microw. Theory Tech., vol. 40, no. 6, pp. 1239-1250, Jun. 1992.

[5] J. O. Mcspadden, T. Yoo, and K. Chang, "Theoretical and experimental investigation of a rectenna element for microwave power transmission," IEEE Trans. Microw. Theory Tech., vol. 40, no. 12, pp. 2359-2366, Dec. 1992.

[6] B. Strassner and K. Chang, "5.8 GHz circularly polarized rectifying antenna for wireless microwave power transmission," IEEE Trans. Microw. Theory Tech., vol. 50, no. 8, pp. 1870-1876, Aug. 2002.

[7] M. A. Kossel, R. Kung, H. Benedickter, and W. Bachtold, "An active tagging system using circular polarization modulation," IEEE Trans. Microw. Theory Tech., vol. 47, no. 12, pp. 1-6, Dec. 1999.
[8] J. Heikkinen and M. Kivikoski, "A novel dual-frequency circularly polarized rectenna," IEEE Antennas Wireless Propag. Lett., vol. 2, no. 1, pp. 330-333, 2003.

[9] M. Ali, R. Dougal, G. Yang, and H.-S. Hwang, "Wideband (5-6 GHz WLAN band) circularly polarized patch antenna for wireless power sensors," in IEEE Antennas and Propagation Society Int. Symp. Dig., vol. 2, Columbus, OH, Jun. 2003, pp. 34-37.

[10] G. Yang, M. Ali, and R. Dougal, "A thin wideband microstrip patch antenna with two adjacent slots," Microw. Opt. Technol. Lett., vol. 41, no. 4, pp. 261-266, May 2004.

[11] C. A. Balanis, Antenna Theory. New York: Wiley, 1997, pp. 70-71, 88. 